\title{
Gamma Knife radiosurgery for glomus jugulare tumors: a single-center series of 75 cases
}

\author{
Ramez Ibrahim, FRCS, ${ }^{1}$ Mohannad B. Ammori, MSc, ${ }^{2}$ John Yianni, FRCS, ${ }^{1}$ Alison Grainger, BSc, ${ }^{1}$ \\ Jeremy Rowe, FRCS, ${ }^{1}$ and Matthias Radatz, FRCS ${ }^{1}$
}

\begin{abstract}
${ }^{1}$ National Centre for Stereotactic Radiosurgery, Royal Hallamshire Hospital, Sheffield; and ${ }^{2}$ Royal Gwent Hospital, Newport, United Kingdom
\end{abstract}

\begin{abstract}
OBJECTIVE Glomus jugulare tumors are rare indolent tumors that frequently involve the lower cranial nerves (CNs). Complete resection can be difficult and associated with lower CN injury. Gamma Knife radiosurgery (GKRS) has established its role as a noninvasive alternative treatment option for these often formidable lesions. The authors aimed to review their experience at the National Centre for Stereotactic Radiosurgery, Sheffield, United Kingdom, specifically the long-term tumor control rate and complications of GKRS for these lesions.
\end{abstract}

METHODS Clinical and radiological data were retrospectively reviewed for patients treated between March 1994 and December 2010. Data were available for 75 patients harboring 76 tumors. The tumors in 3 patients were treated in 2 stages. Familial and/or hereditary history was noted in 12 patients, 2 of whom had catecholamine-secreting and/or active tumors. Gamma Knife radiosurgery was the primary treatment modality in 47 patients (63\%). The median age at the time of treatment was 55 years. The median tumor volume was $7 \mathrm{~cm}^{3}$, and the median radiosurgical dose to the tumor margin was $18 \mathrm{~Gy}$ (range 12-25 Gy). The median duration of radiological follow-up was 51.5 months (range 12-230 months), and the median clinical follow-up was 38.5 months (range 6-223 months).

RESULTS The overall tumor control rate was $93.4 \%$ with low CN morbidity. Improvement of preexisting deficits was noted in 15 patients (20\%). A stationary clinical course and no progression of symptoms were noted in 48 patients $(64 \%)$. Twelve patients (16\%) had new symptoms or progression of their preexisting symptoms. The Kaplan-Meier actuarial tumor control rate was $92.2 \%$ at 5 years and $86.3 \%$ at 10 years.

CONCLUSIONS Gamma Knife radiosurgery offers a risk-versus-benefit treatment option with very low CN morbidity and stable long-term results.

https://thejns.org/doi/abs/10.3171/2016.4.JNS152667

KEY WORDS glomus tumor; Gamma Knife; stereotactic radiosurgery; oncology

$\mathrm{G}$ LOMUS jugulare and tympanicum tumors are also known as skull base nonchromaffin paragangliomas and chemodectomas. They arise from the chemoreceptor paraganglion cells, which are part of the parasympathetic system involved in autonomic regulation of respiration and blood pressure. The glomus jugulare tumor arises from paraganglion cells located in adventitia of the jugular bulb at the jugular foramen. The glomus tympanicum tumor arises from similar cells along Jacobson's nerve, the tympanic branch of the glossopharyngeal nerve, and Arnold's nerve, the auricular branch of the vagus nerve. Other possible locations within the middle ear are in relation to the tympanic canaliculus, the promontory, and the lesser petrosal nerve.
These tumors are rare highly vascular tumors with a reported incidence of 1 case per 1.3 million persons. ${ }^{30}$ They represent $0.6 \%$ of all cranial neoplasms, with the glomus tympanicum tumor being the most common neoplasm of the middle ear. ${ }^{33,43}$ Most of these tumors are benign but locally destructive with an estimated growth rate of $1 \mathrm{~mm}$ per year. ${ }^{38}$ Rare malignant variants $(1 \%-5 \%)$, which can metastasize, have been reported. ${ }^{47}$

These tumors are most common in females in the 5th and 6th decades. ${ }^{18,34,57}$ Presentation at an earlier age in the 3rd decade suggests an underlying genetic mutation of the succinate dehydrogenase (SDH) enzyme with the potential for malignant or aggressive behavior, metastasis, and multicentricity. ${ }^{34}$

ABBREVIATIONS CN = cranial nerve; CSF = cerebrospinal fluid; GKRS = Gamma Knife radiosurgery; $\mathrm{GTR}$ = gross-total resection; $\mathrm{RT}=$ radiotherapy; $\mathrm{SDH}=$ succinate dehydrogenase; $\mathrm{SDHB}=\mathrm{SDH}$ enzyme complex subunit $\mathrm{B}$.

SUBMITTED November 20, 2015. ACCEPTED April 7, 2016.

INCLUDE WHEN CITING Published online July 8, 2016; DOI: 10.3171/2016.4.JNS152667. 
Clinically, patients most commonly present with pulsatile tinnitus, hearing loss, and lower cranial nerve (CN) deficits. Other symptoms are dizziness and localized pain. Presentation with facial nerve weakness occurs rarely and indicates an infiltrative tumor. ${ }^{1,41}$ Large tumors can have significant intracranial and extracranial extensions involving vascular structures of the carotid sheath and causing brainstem compression. Histologically, the tumors are similar to pheochromocytomas, and although the majority are nonfunctioning, they secrete catecholamines in $1 \%-$ $3 \%$ of cases, in which patients may present with symptoms of catecholamine hypersecretion such as hypertension, tachycardia, palpitation, headache, and anxiety. ${ }^{22,34}$

Traditionally, these tumors were resected, but because of their high vascularity and the frequent involvement of the lower CNs, surgery entails significant risk. Whereas microsurgical removal still constitutes a valuable therapeutic option, particularly for giant tumors with significant brainstem compression, in recent years there has been a noticeable shift to treat these lesions with a less invasive treatment, namely radiation. Gamma Knife radiosurgery (GKRS) has been increasingly popular in treating these lesions given its high precision and the sparing of nearby critical structures from the radiation field, with reported successful outcomes. We present a retrospective singlecenter series of cases treated at the stereotactic radiosurgery center in Sheffield, United Kingdom.

\section{Methods}

The National Centre for Stereotactic Radiosurgery database was retrospectively reviewed in 2012 for treated cases of glomus jugulare and tympanicum tumors over a 16-year period between March 1994 and December 2010. No cases were included after this period to allow for sufficient follow-up. The medical notes, procedural details, and most recent clinical and MRI follow-up data were collected and analyzed. When data were deemed not up to date, the most recent clinical and radiological follow-up was actively requested from the referring hospitals. The Royal Hallamshire Hospital Review board approved the study protocol.

\section{Patient Characteristics}

Of 83 total patients, 8 were lost to follow-up with incomplete data. Seventy-six tumors were separately analyzed in the remaining 75 patients, with 1 patient having bilateral tumors (Fig. 1). The patient cohort consisted of 35 males and 40 females. Median age at the time of treatment was 55 years (range 21-84 years). The tumor was on the left side in 40 patients and on the right in 34 patients, and 1 patient had bilateral tumors. This latter patient had been referred after biopsy of a mass in the left ear canal with histology confirming a paraganglioma. Subsequent genetic analysis revealed an SDH enzyme complex subunit B (SDHB) mutation.

A familial paraganglioma history was noted in 12 patients, among whom a hereditary mutation of the mitochondrial SDH enzyme complex mutation deficiency was found in 7 cases after genetic analysis. An SDHB mutation was confirmed in 5 patients and a subunit $\mathrm{C}$ (SDHC)
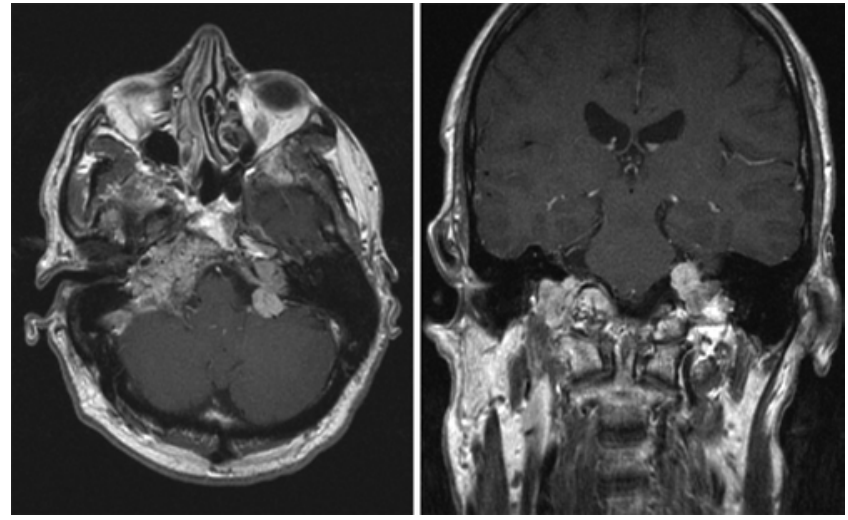

FIG. 1. Axial (left) and coronal (right) post-gadolinium MR images obtained in a patient with bilateral glomus jugulare tumors. A biopsy from the left ear confirmed the diagnosis. Subsequent genetic analysis revealed an SDH enzyme mutation subtype $\mathrm{B}$ (SDHB). The tumors were stationary in size after 24 months of radiological follow-up.

mutation in 2 patients. Two patients had endocrinologically active tumors secreting catecholamine (raised urinary vanillylmandelic acid). Patient characteristics and duration of follow-up are summarized in Table 1.

Among the 75 patients, GKRS was the primary treatment modality in 47 patients (63\%), 14 (18.7\%) of whom had been referred after tumor growth was observed on repeat imaging. Twenty-four patients $(32 \%)$ had undergone prior resection; 1 of these 24 patients had received preoperative radiotherapy (RT) as well, and another patient had undergone a postoperative embolization procedure. Three patients (4\%) underwent embolization only and 1 patient $(1.3 \%)$ received only RT prior to the radiosurgery.

In 50 patients the diagnosis was based on clinical presentation (tinnitus, hearing loss, associated $\mathrm{CN}$ deficits), MRI characteristics (increased T2-weighted signal intensity, decreased T1-weighted signal intensity, and intense enhancement after gadolinium administration), and additional information from CT and cerebral angiography.

Hearing loss (CN VIII) was the most common presenting symptom (63 patients [84\%]), followed by pulsatile tinnitus in 50 patients (66.7\%). Twenty-eight patients (37.3\%) presented with ataxia. The frequency of other $\mathrm{CN}$ deficits before GKRS treatment and not attributed to a post-resection deficit were as follows: $\mathrm{CN} \mathrm{V}, 11$ patients (14.6\%); $\mathrm{CN}$ VI, 1 patient (1.3\%); CN VII, 13 patients (17.3\%); CN IX, 22 patients (29.3); CN X, 25 patients (33.3\%); CN XI, 10 patients (13.3\%); and CN XII, 20 patients (26.7\%). Most patients had more than $1 \mathrm{CN}$ deficit, and various lower $\mathrm{CN}$ deficit combinations were observed in 30 patients (40\%; Table 2).

Among the 24 patients (32\%) who had undergone prior resection, 10 had sustained a postoperative $\mathrm{CN}$ deficit associated with either a single nerve or a combination of nerves. The most commonly noted postoperative deficits were those associated with CN VII in 7 patients, followed by $\mathrm{CN} \mathrm{X}$ in 6 patients (transient vocal cord paresis that improved prior to GKRS in 1 patient), CN IX in 4 patients, CN VIII in 2 patients, and CNs V, XI, and XII in 1 patient each. None of these patients later showed any 
TABLE 1. Summary of patient demographics and duration of follow-up

\begin{tabular}{ll}
\hline \multicolumn{1}{c}{ Parameter } & \multicolumn{1}{c}{ Value } \\
\hline No. of patients & \multicolumn{1}{c}{75} \\
\hline Median age in yrs (range) & $55(21-84)$ \\
\hline M/F (no. [\%]) & $35(46.6) / 40(53.4)$ \\
\hline $\begin{array}{l}\text { Lesion side: It/rt/bilat (no. [\%]) } \\
\text { Familial or hereditary lesion: proven/un- } \\
\quad \text { proven (no. [\%]) }\end{array}$ & $12(163.4) / 34(45.3) / 1(1.3)$ \\
\hline $\begin{array}{l}\text { Histological confirmation: yes/no (no. [\%]) } \\
\text { Median radiological FU in mos (range) }\end{array}$ & $25(33.3) / 50(66.7)$ \\
\hline $\begin{array}{l}\text { Radiological FU in yrs (no. [\%]): } \\
<5 / 5-10 />10\end{array}$ & $41(54.6) / 21(28) / 13(17.4)$ \\
\hline $\begin{array}{l}\text { Median clinical FU in mos (range) } \\
\text { Clinical FU in yrs (no. [\%]): <5/5-10/>10 }\end{array}$ & $38.5(6-223)$ \\
\hline
\end{tabular}

$\mathrm{FU}=$ follow-up.

improvement in their preexisting deficits after GKRS, and 1 patient experienced transient worsening of preexisting CN VII dysfunction.

\section{Radiosurgical Procedure}

Leksell Gamma Knife Models S, C, 4C, and Perfexion (Elekta $\mathrm{AB}$ ) were used to administer treatment over the specified timeframe. The Leksell stereotactic frame was affixed after a local anesthetic was applied, followed by the acquisition of thin 1-mm-slice MRI sequences (T1and T2-weighted, fat suppression, and post-gadolinium T1weighted). Gamma Knife radiosurgery dose planning was performed by a team comprising a neurosurgeon, neuroradiologist, and medical physicist. Seventy-six tumors were treated in 75 patients. The radiosurgery treatments were performed in a single session in 73 cases and as a 2-staged treatment in 3 cases. The radiosurgical treatment data parameters were analyzed in terms of individual tumors.

The median tumor volume was $7 \mathrm{~cm}^{3}$ (range 0.2-53.9 $\mathrm{cm}^{3}$ ). A median number of 11 isocenters (range 2-44) was used in dose delivery. The median tumor margin dose was 18 Gy (range 12-25 Gy) and was prescribed to the 50\% isodose line (range 40\%-56\%) in 59 tumors (Table 3). After our initial experience in 13 cases treated using the Model S Gamma Knife during the first 7 years of the study period, we adjusted the protocol to deliver a significantly lower margin dose to the tumors. With technical improvements, a higher number of isocenters has also been used.

\section{Clinical and Radiological Evaluation}

Clinical outcome was assessed through neurological examination including $\mathrm{CN}$ function every 6 months for the first 2 years and on a yearly basis thereafter. The patients' neurological condition prior to GKRS treatment served as a baseline and after treatment was described as unchanged, improved, or worse, depending on whether there were new symptoms or progression of preexisting symptoms. Posttreatment complications were classified as transient or permanent. Tumor was typed according to the Glasscock-
TABLE 2. Presenting symptoms

\begin{tabular}{cc}
\hline \multicolumn{1}{c}{ Symptom } & No. of Patients (\%) \\
\hline CN neuropathy prior to GKRS* & \\
\hline V & $11(14.6)$ \\
\hline VI & $1(1.3)$ \\
\hline VII & $13(17.3)$ \\
\hline VIII & $63(84)$ \\
\hline IX & $22(29.3)$ \\
\hline X & $25(33.3)$ \\
\hline XI & $10(13.3)$ \\
\hline XII & $20(26.7)$ \\
\hline Lower CN (IX-XII) combinations & $30(40)$ \\
\hline Tinnitus & $50(66.6)$ \\
\hline Ataxia & $28(37.3)$ \\
\hline
\end{tabular}

* Not attributed to postsurgical deficit.

Jackson classification: ${ }^{35}$ Type I (small tumor involving the jugular bulb, middle ear, and mastoid); Type II (tumor extending under the internal auditory canal); Type III (tumor extending into the petrous apex); and Type IV (tumor extending beyond the petrous apex into the clivus or infratemporal fossa). The Fisch classification was applied as well: ${ }^{52}$ Type A (tumor limited to the middle ear cleft); Type B (tumor limited to the tympanomastoid area); Type C (tumor involving the infralabyrinthine compartment of the temporal bone and extending into the petrous apex); Type D1 (tumor with an intracranial extension $<2 \mathrm{~cm}$ in diameter); and Type D2 (tumor with an intracranial extension > $2 \mathrm{~cm}$ in diameter). The number and percentage of tumors in each category are presented in Table 4 . The ability to treat extensive tumors with downward extension into the cervical region is pertinent to GKRS. Hence, in addition to the above classifications, we categorized tumors according to their location and extent of caudal extracranial cervical tumor extension. After treatment tumors were classified by location after reviewing coronal post-gadolinium administration MR images: skull base (with no cervical extension), extracranial cervical extension to the upper border of the first cervical (C-1) vertebra, upper border of the second cervical (C-2) vertebra, or upper border of the third cervical (C-3) vertebra (Table 4).

The patients underwent radiological follow-up with T1weighted, T2-weighted, and post-gadolinium T1-weighted MRI at 6-month intervals during the 1st year and then yearly thereafter. Where possible, contrast-enhanced T1 volume scans were used to generate a 3D tumor volume for comparison with the GammaPlan treatment volume measurements. In some cases follow-up imaging was performed at a remote center with protocols that differed from our own, in which case anteroposterior, lateral, and vertical diameters were obtained; a change greater than $2 \mathrm{~mm}$ was regarded as a real change in tumor size. After documented tumor control (stationary or decreased tumor size) and a satisfactory neurological condition (unchanged or improved) over a 5-year period, the imaging interval could be changed to 2 yearly scans in the majority of patients. All patients underwent regular periodic MRI examina- 
TABLE 3. Gamma Knife radiosurgery treatment parameters

\begin{tabular}{lc}
\hline \multicolumn{1}{c}{ Parameter } & Value \\
\hline GKRS tumor margin dose in Gy & $18.3 \pm 3.0$ \\
Mean \pm SD & 18 \\
Median & $12-25$ \\
Range & \\
GKRS max dose in Gy & $37.2 \pm 6.3$ \\
Mean \pm SD & 36.7 \\
Median & $23.2-50$ \\
Range & \\
Prescription Isodose line in \% & $49.6 \pm 2.3$ \\
Mean \pm SD & 50 \\
Median & $40-56$ \\
Range & $12.1 \pm 7.2$ \\
No. of isocenters & 11 \\
Mean \pm SD & $2-44$ \\
Median & \\
Range & $9.1 \pm 8.5$ \\
\hline Tumor vol at GKRS in $\mathrm{cm}^{3}$ & 7.0 \\
Mean \pm SD & $0.2-53.9$ \\
Median & $8.6 \pm 6.4$ \\
Range* & 7.4 \\
Treatment vol at GKRS in $\mathrm{cm}^{3}$ & $0.2-32.9$ \\
Mean \pm SD & \\
Median & \\
Range* & \\
\hline
\end{tabular}

$\mathrm{SD}=$ standard deviation

* Disparity in ranges due to incomplete coverage of tumors extending extracranially.

tions. Data from repeated clinical examinations were not always available, probably reflecting an absence of new symptoms. Thus, the median radiological follow-up was 51.5 months (range 12-230 months), whereas the median clinical follow-up was 38.5 months (range 6-223 months).

\section{Statistical Analysis}

Data were analyzed using the software package IBM SPSS version 22 (IBM Corp.). Univariate analysis was undertaken using the log-rank test for categorical data and Cox regression for continuous data, as appropriate. Variables identified with a $\mathrm{p}<0.1$ were included in a multivariate Cox proportional-hazards regression analysis to determine the independent predictors of radiological and clinical progression-free survival. Significance was accepted at $\mathrm{p}<0.05$. Hazard ratios and $95 \%$ confidence intervals were documented. A Kaplan-Meier survival analysis was undertaken to show the radiological progression-free survival. The variables included in the analysis were age, sex, prior treatment (surgery, embolization, or RT), familial history, Glasscock-Jackson and Fisch types, and tumor location (skull base vs extracranial cervical extension to the upper border of the C-1, C-2, or C-3 vertebra). The clinical variables included were presentations with tinnitus or lower $\mathrm{CN}$ deficit. The GKRS treatment variables selected were tumor volume, margin dose, maximal dose, and number of isocenters.
TABLE 4. Summary of tumor grades and location

\begin{tabular}{lc}
\hline \multicolumn{1}{c}{ Parameter } & No. (\%) \\
\hline No. of tumors & 76 \\
\hline $\begin{array}{l}\text { Glasscock-Jackson type: } \\
\text { I/II/III/IV }\end{array}$ & $11(14.5) / 16(21.1) / 16(21.1) / 33(43.4)$ \\
\hline $\begin{array}{l}\text { Fisch type: A/B/C/D1/D2 } \\
\text { Tumor location: skull } \\
\text { base/C-1/C-2/C-3 }\end{array}$ & $2(2.6) / 17(22.3) / 30(39.4) / 20(26.3) / 7(9.2)$ \\
\hline
\end{tabular}

\section{Results \\ Tumor Control}

On the last follow-up MR images, 43 tumors (56.6\%) had decreased in size, 28 (36.8\%) tumors were unchanged, and $5(6.6 \%)$ had increased in size. Thus, overall tumor control was achieved in 71 tumors (93.4\%). Actuarial progression-free survival was $97.2 \%, 92.2 \%$, and $86.3 \%$ at 2, 5, and 10 years, respectively (Fig. 2). Of the 5 growing tumors, 2 had salvage treatments, one with repeated GKRS and one with fractionated RT. The patients in the 3 remaining cases were still under observation for minimal increases in tumor size. This study included 13 patients whose follow-ups were longer than 10 years' duration; the tumors reduced in size in 10 of the patients and were unchanged in 3.

Previous treatment $(\mathrm{p}=0.060)$ and extracranial cervical extension $(\mathrm{p}=0.077)$ tended to be associated with poorer tumor control (Table 5). Specifically, 2 of the 5 cases with observed tumor growth had extracranial tumor extending below $\mathrm{C}-3$, and the growth appeared to be outside the radiosurgically treated field. The Glasscock-Jackson and Fisch classifications (both of which describe the cranial extent of these tumors) were not related to outcome. Moreover, outcome was not related to tumor volume or prescribed dose. In this study, cases with a familial history or SDH mutation were not associated with poorer outcomes than cases of sporadic tumors. No dependent predictors reached statistical significance $(p<0.05)$ on the multivariate Cox regression statistical model for tumor progression-free survival.

With regard to the 2 catecholamine-secreting tumors noted in the present series, 1 case was published as a case report with a successful reduction in tumor volume in a 37-year-old female patient and the attainment of nearnormal levels of urinary catecholamine excretion after 37 months. ${ }^{22}$ The second patient was a 60 -year-old male patient who had presented with hearing loss, tinnitus, and facial numbness (CN V). Hypertension, atrial fibrillation, and anxiety had also been diagnosed. High levels of metanephrines and vanillylmandelic acid were detected in his urine. After 49 months of radiological follow-up after treatment, his tumor had reduced in size; his symptoms related to catecholamine hypersecretion tailored off on clinical follow-up as well (Fig. 3).

\section{Clinical Outcome}

Fifteen patients (20\%) reported improvement in their 


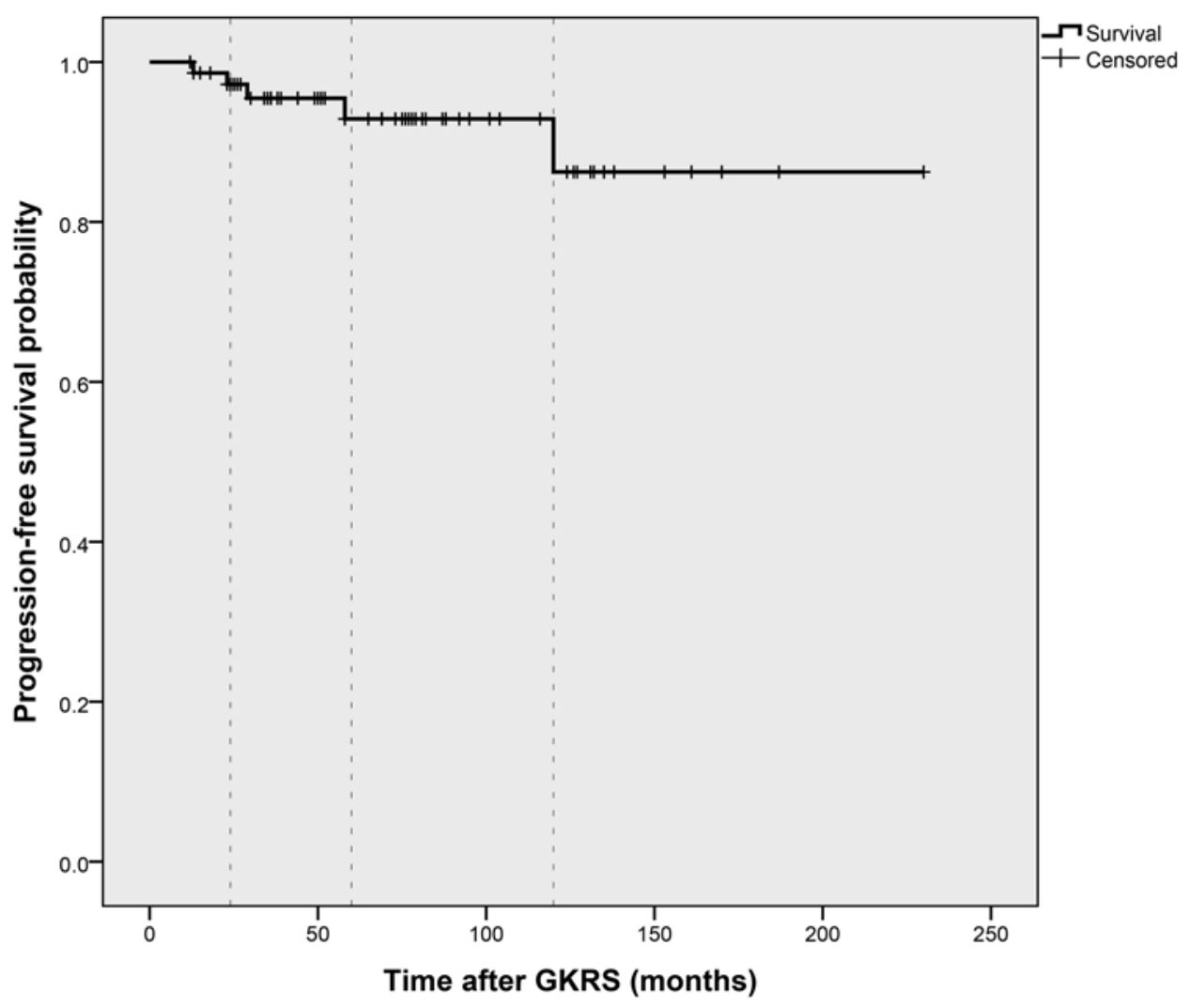

FIG. 2. Tumor progression-free survival after GKRS.

pretreatment symptoms, with the resolution of pulsatile tinnitus in 6 of the patients and hearing improvement in 3. Forty-eight patients (64\%) reported their initial symptoms as unchanged. Twelve patients (16\%) reported a worsening of clinical symptoms after treatment, but a new permanent $\mathrm{CN}$ deficit was noted in only 2 patients. In 1 of these patients the deficit was a vocal cord paresis, which was treated with speech therapy; in the other patient a partial facial nerve palsy developed. In both patients tumor growth was controlled. In the remainder of the patients, the $\mathrm{CN}$ morbidity was transient and onset occurred within 5-8 months after treatment. A transient new $\mathrm{CN}$ deficit (V, VII, X) was observed in 4 patients. Transient worsening of preexisting CN VII and CN X function was noted in 6 patients, with the facial nerve being the most commonly affected in 3 patients. These patients were prescribed a short (1-2 weeks) course of steroids (dexamethasone), which gradually helped restore $\mathrm{CN}$ function to pretreatment levels. Transient worsening of the more subjective symptoms of dizziness and unsteadiness was reported in 5 patients.

In this study, larger tumor volumes $\left(>7 \mathrm{~cm}^{3}\right)$ were associated with an increased risk of $\mathrm{CN}$ damage $(\mathrm{p}=0.038)$, and the presence of $\mathrm{CN}$ deficits before radiosurgery was associated with an increased risk of $\mathrm{CN}$ deficits after radiosurgery $(p=0.027)$. This was significant on both univariate and multivariate analysis (Table 6).

Five patients died of unrelated causes during the study period.

\section{Discussion}

Glomus jugulare tumors are rare and their management remains controversial as existing studies addressing the various treatment options are retrospective reports with a few systematic meta-analyses on each therapeutic modality. ${ }^{43}$ The treatment options are resection, RT, stereotactic $\mathrm{RT}$, radiosurgery, and continued observation or conservative management. Their treatment is becoming increasingly multidisciplinary, and several factors are taken into consideration during decision making: patient age, physical condition, tumor size, lesion growth rate, presenting symptoms and preexisting $\mathrm{CN}$ deficits, comorbidities, familial and/or hereditary history, and, in particular, the desires and expectations of patients regarding their functional outcome.

Traditionally, resection with adjunctive preoperative embolization constituted the mainstay of treatment aiming to achieve a "cure" by complete tumor removal. This therapeutic modality has proven difficulty and complexity due to the frequent lower $\mathrm{CN}$ involvement as these tumors are noted to infiltrate between the $\mathrm{CN}$ fascicles and perineurium with reactive fibrosis even when the nerves are still functioning, ${ }^{12,57}$ rendering complete resection occasionally impossible without sacrificing these nerves. ${ }^{60}$ Moreover, preoperative embolization does not reduce the risk of new postoperative $\mathrm{CN}$ deficits ${ }^{49}$ and in itself carries a risk of permanent cranial neuropathy because of the overlapping blood supply between these tumors and the CNs. ${ }^{25,26}$ 
TABLE 5. Factors predictive of radiological tumor progressionfree survival

\begin{tabular}{|c|c|c|c|}
\hline Variable & $\mathrm{HR}$ & $95 \% \mathrm{Cl}$ & $\mathrm{p}$ Value \\
\hline \multicolumn{4}{|l|}{ Univariate analysis } \\
\hline Age $(\leq 55$ vs $>55$ yrs $)$ & 0.820 & $0.127-5.307$ & 0.835 \\
\hline Male & 0.821 & $0.136-4.949$ & 0.829 \\
\hline Previous treatment & 0.020 & $0.000-32.697$ & 0.060 \\
\hline Hereditary lesion & 1.390 & $0.155-12.452$ & 0.768 \\
\hline Tinnitus & 0.541 & $0.087-3.358$ & 0.503 \\
\hline Lower CN deficit & 2.271 & $0.376-13.705$ & 0.358 \\
\hline Tumor vol $\left(\leq 7\right.$ vs $\left.>7 \mathrm{~cm}^{3}\right)$ & 1.507 & $0.251-9.060$ & 0.652 \\
\hline Margin dose ( $\leq 18$ vs >18 Gy) & 0.670 & $0.111-4.025$ & 0.659 \\
\hline Max dose & 0.903 & $0.777-1.050$ & $0.186^{*}$ \\
\hline No. of isocenters & 1.047 & $0.931-1.177$ & $0.445^{\star}$ \\
\hline Glasscock-Jackson type & 0.796 & $0.361-1.754$ & 0.152 \\
\hline Fisch type & 0.822 & $0.270-2.497$ & 0.546 \\
\hline $\begin{array}{l}\text { Location (intracranial vs extracra- } \\
\text { nial extension to } \mathrm{C}-1, \mathrm{C}-2, \mathrm{C}-3 \text { ) }\end{array}$ & 1.636 & $0.741-3.612$ & 0.077 \\
\hline \multicolumn{4}{|l|}{ Multivariate analysis } \\
\hline Previous treatment & - & - & 0.964 \\
\hline $\begin{array}{l}\text { Location (intracranial vs extracra- } \\
\text { nial extension to C-1, C-2, C-3) }\end{array}$ & 2.040 & $0.801-5.199$ & 0.135 \\
\hline
\end{tabular}

In published surgical series, $1,9,18,36,37,53,54,57,58,67,68$ the results of total resection vary between $76 \%$ and $96 \%$. Reported recurrence rates are between $7 \%$ and $10 \%$ with a median time to recurrence of 5.8 years in one study. ${ }^{37}$ Rates of postoperative CSF leaks vary between $3.7 \%{ }^{58}$ and $17.6 \%,{ }^{9}$ and rates of new postoperative lower $\mathrm{CN}$ deficits varied between $10 \%{ }^{57}$ and $47 \%$ in an early series by Jackson et al. ${ }^{36}$ Mortality rates can be as high as $4.2 \% .{ }^{57}$ The surgical morbidity associated with damage to the lower CNs invariably requires early postoperative tracheostomy and feeding gastrostomy to prevent aspiration pneumonia, laryngeal injection for vocal cord paresis, and intensive postoperative rehabilitation. ${ }^{18,50,57}$ It was also noted that patients with large tumors will have some degree of preoperative vagal dysfunction with expected postoperative dysphagia. ${ }^{12,50}$

Despite the significant surgical advances and intraoperative aids such as electrophysiological monitoring, surgical morbidity and mortality remained relatively high. In 2012 Makiese et al. ${ }^{46}$ reported on a surgical series of 75 cases in which gross-total resection (GTR) was achieved in $78.7 \%$ of cases. The rates of lower $\mathrm{CN}$ deficits were $6.6 \%$; CSF leak, $5.3 \%$; and mortality, $2.7 \%$.

There is, of course, the question of whether one should simply observe these tumors. However, they do grow, albeit at a very slow rate, and a watch-and-wait policy may increase the risks of subsequent interventions as the lesions gradually attain a larger size and infiltrate surrounding structures. Hence, conservative management is usually reserved for elderly patients or those who do not desire treatment. ${ }^{64}$

To avoid and minimize the potential for iatrogenic $\mathrm{CN}$
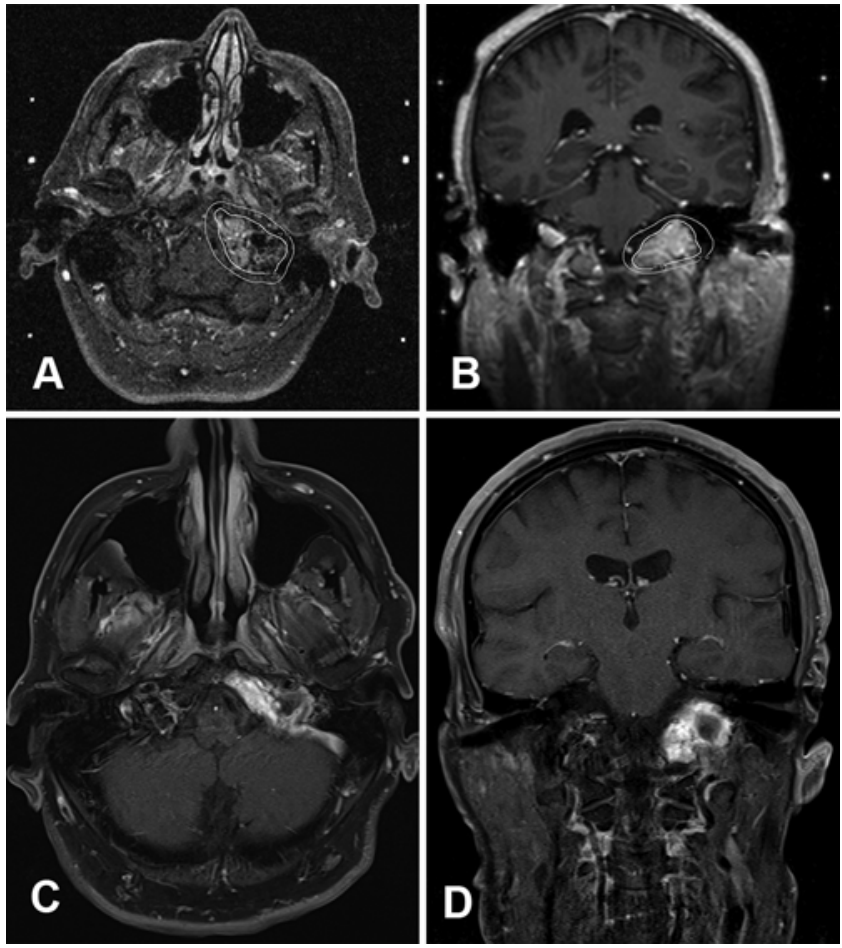

FIG. 3. Treatment planning axial (A) and coronal (B) post-gadolinium MR images, and follow-up (49 months posttreatment) axial (C) and coronal (D) post-gadolinium MR images.

injury with the resultant loss of quality of life and risk of mortality, there has been a noticeable paradigm shift to instead perform a function-preserving subtotal resection aimed at achieving a satisfactory and safe decompression, followed by postoperative RT, ${ }^{18,66}$ GKRS, ${ }^{38,39,52}$ or a watchand-wait policy for tumor remnants. This strategy has been recommended particularly for large complex tumors and, by some authors, for elderly patients. ${ }^{15,69}$ Fortunately, the occurrence of large tumors with significant brainstem compression and dural invasion remains relatively rare and even more so in recent years because of earlier radiological diagnosis. ${ }^{1,12}$

Glomus tumors are considered to be relatively radiosensitive,${ }^{14}$ and radiation treatment modalities aim to arrest tumor growth and achieve local tumor control. Among these modalities, GKRS has emerged as an attractive minimally invasive treatment with an established role for more than 2 decades. The main advantages are its high precision with frame application and dose delivery to a prescribed tumor volume with a steep dose drop-off resulting in negligible radiation toxicity and $\mathrm{CN}$ morbidity. ${ }^{31,43} \mathrm{In}$ addition, it is performed in a single treatment session, although staged treatments can be performed for larger tumors. GKRS has been increasingly indicated as a primary treatment, as well as a salvage treatment for residual and recurrent tumors after previous resection.

In all published GKRS studies, there were essentially no cases of treatment-related mortality and very low $\mathrm{CN}$ morbidity, cases of which were mostly temporary. The lower CNs have been noted to tolerate a radiation dose of up to $25 \mathrm{~Gy}$, although transient radiation-induced $\mathrm{CN}$ neu- 
TABLE 6. Factors predictive of clinical progression-free survival

\begin{tabular}{|c|c|c|c|}
\hline Variable & $\mathrm{HR}$ & $95 \% \mathrm{Cl}$ & p Value* \\
\hline \multicolumn{4}{|l|}{ Univariate analysis } \\
\hline Age $(\leq 55$ vs $>55$ yrs $)$ & 2.058 & $0.570-7.431$ & 0.262 \\
\hline Male & 2.381 & $0.686-8.265$ & 0.160 \\
\hline Previous treatment & 0.563 & $0.149-2.135$ & 0.392 \\
\hline Hereditary lesion & 1.597 & $0.418-6.108$ & 0.490 \\
\hline Tinnitus & 0.420 & $0.110-1.607$ & 0.193 \\
\hline Vertigo & 0.596 & $0.157-2.255$ & 0.441 \\
\hline Lower $\mathrm{CN}$ deficit & 3.865 & $1.118-13.360$ & 0.022 \\
\hline Tumor vol ( $\left.\leq 7 \mathrm{vs}>7 \mathrm{~cm}^{3}\right)$ & 4.810 & $1.034-22.373$ & 0.027 \\
\hline Margin dose ( $\leq 18$ vs $>18$ Gy) & 0.444 & $0.128-1.535$ & 0.188 \\
\hline Max dose & 0.937 & $0.853-1.028$ & $0.169 \dagger$ \\
\hline No. of isocenters & 1.062 & $0.976-1.156$ & $0.163 \dagger$ \\
\hline Glasscock-Jackson type & 2.740 & $0.946-7.935$ & 0.221 \\
\hline Fisch type & 2.584 & $0.911-7.329$ & 0.337 \\
\hline $\begin{array}{l}\text { Location (intracranial vs } \\
\text { extracranial extension to } \\
\text { C-1, C-2, C-3) }\end{array}$ & 1.684 & $0.990-2.864$ & 0.191 \\
\hline \multicolumn{4}{|l|}{ Multivariate analysis } \\
\hline Tumor vol & 5.129 & $1.092-24.092$ & 0.038 \\
\hline Lower $\mathrm{CN}$ deficit & 4.175 & $1.181-14.755$ & 0.027 \\
\hline
\end{tabular}

ropathy can occur with lower doses ${ }^{59}$ Early and midterm GKRS reports were encouraging with reported tumor control rates of $100 \%$ across 11 studies , $^{7,16,19-21,24,42,45,59,61,62}$ and over $94 \%$ in 2 studies over a median duration of 3.5 years of follow-up. ${ }^{27,55}$ Only 3 studies reported tumor control rates below $90 \% .^{13,39,65}$ Because of an observed growth rate of $0.8 \mathrm{~mm}$ per year and a tumor doubling time of approximately 10 years (median 4.2 years), ${ }^{38}$ these earlier reports and later reviews recommended longer follow-ups to establish whether tumor control is maintained. ${ }^{40}$ Two preliminary studies were performed by Eustacchio et al. ${ }^{17}$ and Gerosa et al. ${ }^{28}$ with tumor control rates of $95 \%$ over a median follow-up longer than 4 years.

Studies with longer follow-up intervals have been published, confirming maintained tumor control against the natural history of the disease. The largest study to date, performed under the auspices of the North American Gamma Knife Consortium, is the multicenter analysis by Sheehan et al..$^{63}$ in which 132 patients were followed up for a median duration of 4.2 years and in whom overall tumor control was 93\%. Improvement in preexisting $\mathrm{CN}$ deficits was observed in $11 \%$ of patients, and new or progressive $\mathrm{CN}$ deficits were noted in only $15 \%$, with no deaths. More recently, 2 additional retrospective series reported tumor control rates of $95 \%$ and $94.8 \%$ over a median follow-up of 9.8 years and a mean follow-up of 7.2 years, respectively. ${ }^{23,44}$ Gamma Knife radiosurgery studies are summarized in Table 7.

The current study contributes to the literature by confirming stable long-term results after GKRS. The overall rate of tumor control was $93.4 \%$ over a median follow-up of 51.5 months. We observed a new $\mathrm{CN}$ deficit in only 2 patients. The outcome rates are better and the $\mathrm{CN}$ complication rates are far lower than those following surgical treatment and with much less of an impact on patient quality of life. In the future, better imaging with more complex plans utilizing a greater number of isodose centers may further improve results in terms of $\mathrm{CN}$ morbidity, as now we would routinely identify the facial nerve and plan around this.

There are issues in terms of tumor size and extent. Our results suggest specifically that there may be more $\mathrm{CN}$ morbidity for larger tumors and that tumors with a greater caudal extent may have poorer control rates. These observations may justify earlier intervention. Our study supports the findings of previous authors that the surgical classification types of Glasscock-Jackson and Fisch have no correlates with outcome after GKRS. ${ }^{59,63}$ Because glomus jugulare tumors spread into the path of least resistance, they can potentially extend downward along the carotid sheath. ${ }^{56}$ This caudal extension may be a limiting factor in the efficacy of GKRS due to the target reach ability of some specific Gamma Knife models as experienced in our series; however, evolving platforms for delivering radiosurgery treatments may allow this issue to be better addressed in the future.

The genetic predisposition of these tumors has been an adverse prognostic factor, with hereditary and/or familial forms tending to occur at an earlier age, presenting as bilateral disease, exhibiting aggressive behavior, having high recurrence rates, and having an association with pheochromocytoma. ${ }^{6} \mathrm{Up}$ to $30 \%$ of paragangliomas are genetically determined by loci on chromosomes $11 \mathrm{q}$ and $1 \mathrm{q}^{6,10}$ with mutations in 6 susceptibility genes of the mitochondrial enzyme complex II, which behave like tumor suppressor genes, identified: SDHD, ${ }^{5}$ SDHB,${ }^{3}$ SDHC, ${ }^{51}$ SDHA, ${ }^{11}$ SDHAF2, ${ }^{32}$ and VHL. ${ }^{8}$ The aggressive variant with metastatic potential had been linked to the SDHB subtype, which was prognostic for malignant behavior, recurrence, and risk of death in one multicenter study. ${ }^{2,10}$ But while these factors may affect the natural history of the disease, in the present study, they did not negatively impact the clinical results achieved. In the subgroup of 12 patients (16\%) in which a familial history of paraganglioma was identified and all patients were alive at the date of their last followup, tumor control was observed in all except one patient with an SDHB mutation who had developed "out of the radiation field" growth from an extracranial cervical extension of the tumor. The patient subsequently underwent repeat GKRS for the entire tumor volume resulting in later volume reduction.

No factors correlating with tumor progression-free survival were identified on statistical analysis; however, the absence of lower $\mathrm{CN}$ involvement at presentation and a tumor volume less than $7 \mathrm{~cm}^{3}$ correlated with a greater likelihood of either an improvement or no progression of symptoms.

The disadvantages of this study are its retrospective nature and the fact that its data were obtained from a single center. We acknowledge that because some patients were not followed up locally, the possibility of variation in follow-up data is introduced; however, the variables recorded for patient follow-up were standardized.

Of note, similar good control rates have been reported 
TABLE 7. Summary of published GKRS studies

\begin{tabular}{|c|c|c|c|c|c|}
\hline Authors \& Year & $\begin{array}{l}\text { No. of } \\
\text { Patients }\end{array}$ & $\begin{array}{l}\text { Margin Dose } \\
\text { (Gy) }\end{array}$ & $\mathrm{FU}(\mathrm{mos})$ & $\begin{array}{c}\text { Tumor } \\
\text { Control Rate }\end{array}$ & $\begin{array}{l}\text { Rate of Clinical Deterioration Reported } \\
\text { Post-GKRS (transient \& permanent) }\end{array}$ \\
\hline Present study & 75 & Median 18 & Median 51.5 & $93.4 \%$ & $17 \%$ \\
\hline Liscak et al., 2014 & 44 & Median 20 & Median 118 & $98 \%$ & $4 \%$ \\
\hline Gandía-González et al., 2014 & 58 & Mean 13.6 & Mean 86.4 & $94.8 \%$ & $8.6 \%$ \\
\hline Sheehan et al., $2012^{*}$ & 132 & Median 15 & Median 50.5 & $93 \%$ & $15 \%$ \\
\hline Lee et al., 2011 & 14 & Mean 13.7 & Median 40.3 & $100 \%$ & $7 \%$ \\
\hline Chen et al., 2010 & 15 & Mean 14.6 & Mean 43.2 & $80 \%$ & $11 \%$ \\
\hline Genç et al., 2010 & 18 & Mean 15.6 & Median 41.5 & $94.4 \%$ & $5.5 \%$ \\
\hline Miller et al., 2009 & 5 & Mean 15 & Mean 34 & $100 \%$ & $0 \%$ \\
\hline Ganz \& Abdelkarim, 2009 & 14 & Mean 13.6 & Mean 28 & $100 \%$ & $7 \%$ \\
\hline Sharma et al., 2008 & 13 & Mean 16.3 & Median 24 & $100 \%$ & $7.7 \%$ \\
\hline Bitaraf et al., 2006 & 14 & Median 18 & Median 18.5 & $100 \%$ & $0 \%$ \\
\hline Varma et al., 2006 & 17 & Median 15 & Median 48 & $76.4 \%$ & $11.8 \%$ \\
\hline Feigl \& Horstmann, 2006 & 12 & Mean 17 & Mean 33 & $100 \%$ & $8.3 \%$ \\
\hline Gerosa et al., 2006 & 20 & Mean 17.3 & Median 50.9 & $95 \%$ & $10 \%$ \\
\hline Sheehan et al., 2005 & 8 & Median 15 & Median 32 & $100 \%$ & $0 \%$ \\
\hline Pollock, 2004 & 39 & Mean 14.9 & Mean 44 & $98 \%$ & $15 \%$ \\
\hline Eustacchio et al., 2002 & 19 & Median 14 & Median 86.4 & $94.7 \%$ & $0 \%$ \\
\hline Foote et al., 2002 & 25 & Median 15 & Median 73 & $100 \%$ & $0 \%$ \\
\hline Saringer et al., 2001 & 13 & Median 12 & Mean 50 & $100 \%$ & $15 \%$ \\
\hline Jordan et al., 2000 & 8 & Median 16.3 & Mean 27 & $33 \%$ & $12.5 \%$ \\
\hline Liscak et al., 1999* & 52 & Median 16.5 & Median 24 & $100 \%$ & $5.8 \%$ \\
\hline Eustacchio et al., 1999 & 10 & Median 13.5 & Median 37.6 & $100 \%$ & $0 \%$ \\
\hline Foote et al., 1997 & 9 & Median 15 & Median 17 & $100 \%$ & $0 \%$ \\
\hline
\end{tabular}

* Multicenter study.

with the use with the use of linear accelerator and CyberKnife radiosurgery technologies. In a systematic review and meta-analysis of 19 available radiosurgical series including such technologies and comprising 335 patients, Guss et al. ${ }^{31}$ reported a tumor control rate of $97 \%$ and a clinical control rate of $95 \%$ across all studies.

Lastly, it is worth mentioning that in an earlier comparative study of results between radiosurgery and microsurgical resection, ${ }^{29} 374$ patients were treated with surgery; the rate of GTR at the primary surgery was $88.2 \%$, and new postoperative $\mathrm{CN}$ deficits occurred in $22 \%-59 \%$ patients, CSF leak in $8.3 \%$, and death in $1.3 \%$. The recurrence rate was $3.1 \%$. Conversely, in 142 patients treated with GKRS, the tumor control rate was $97.8 \%$, clinical improvement was noted in $39 \%$, the morbidity rate was $8.5 \%$, and there were no deaths.

\section{Conclusions}

Gamma Knife radiosurgery is a safe and effective primary treatment as well as salvage therapy for residual and recurrent cases of glomus jugulare and tympanicum tumors. It offers a low risk-versus-benefit treatment option with stable long-term tumor control rates and minimal side effects. Treatment at an early stage before tumors attain a large size potentially reduces posttreatment complications. Catecholamine-secreting tumors respond to GKRS with size reduction, although there is a latency period for hormone level normalization. This series, to the best of our knowledge, constitutes the largest single-center study. It confirms and validates the findings of previously published series.

\section{References}

1. Al-Mefty O, Teixeira A: Complex tumors of the glomus jugulare: criteria, treatment, and outcome. J Neurosurg 97:1356-1366, 2002

2. Amar L, Baudin E, Burnichon N, Peyrard S, Silvera S, Bertherat J, et al: Succinate dehydrogenase B gene mutations predict survival in patients with malignant pheochromocytomas or paragangliomas. J Clin Endocrinol Metab 92:38223828, 2007

3. Astuti D, Latif F, Dallol A, Dahia PL, Douglas F, George E, et al: Gene mutations in the succinate dehydrogenase subunit SDHB cause susceptibility to familial pheochromocytoma and to familial paraganglioma. Am J Hum Genet 69:49-54, 2001

4. Basma NJ, Robin PE: Glomus jugulare tumour masquerading as 'idiopathic' facial nerve palsy. J Laryngol Otol 101:605606, 1987

5. Baysal BE, Ferrell RE, Willett-Brozick JE, Lawrence EC, Myssiorek D, Bosch A, et al: Mutations in SDHD, a mitochondrial complex II gene, in hereditary paraganglioma. Science 287:848-851, 2000

6. Bikhazi PH, Roeder E, Attaie A, Lalwani AK: Familial paragangliomas: the emerging impact of molecular genetics on evaluation and management. Am J Otol 20:639-643, 1999 
7. Bitaraf MA, Alikhani M, Tahsili-Fahadan P, Motiei-Langroudi R, Zahiri A, Allahverdi M, et al: Radiosurgery for glomus jugulare tumors: experience treating 16 patients in Iran. J Neurosurg 105 Suppl:168-174, 2006

8. Boedeker CC, Erlic Z, Richard S, Kontny U, Gimenez-Roqueplo AP, Cascon A, et al: Head and neck paragangliomas in von Hippel-Lindau disease and multiple endocrine neoplasia type 2. J Clin Endocrinol Metab 94:1938-1944, 2009

9. Borba LA, Araújo JC, de Oliveira JG, Filho MG, Moro MS, Tirapelli LF, et al: Surgical management of glomus jugulare tumors: a proposal for approach selection based on tumor relationships with the facial nerve. J Neurosurg 112:88-98, 2010

10. Burnichon N, Abermil N, Buffet A, Favier J, GimenezRoqueplo AP: The genetics of paragangliomas. Eur Ann Otorhinolaryngol Head Neck Dis 129:315-318, 2012

11. Burnichon N, Brière JJ, Libé R, Vescovo L, Rivière J, Tissier $\mathrm{F}$, et al: SDHA is a tumor suppressor gene causing paraganglioma. Hum Mol Genet 19:3011-3020, 2010

12. Carlson ML, Driscoll CL, Garcia JJ, Janus JR, Link MJ: Surgical management of giant transdural glomus jugulare tumors with cerebellar and brainstem compression. J Neurol Surg B Skull Base 73:197-207, 2012

13. Chen PG, Nguyen JH, Payne SC, Sheehan JP, Hashisaki GT: Treatment of glomus jugulare tumors with Gamma Knife radiosurgery. Laryngoscope 120:1856-1862, 2010

14. Cole JM, Beiler D: Long-term results of treatment for glomus jugulare and glomus vagale tumors with radiotherapy. Laryngoscope 104:1461-1465, 1994

15. Cosetti M, Linstrom C, Alexiades G, Tessema B, Parisier S: Glomus tumors in patients of advanced age: a conservative approach. Laryngoscope 118:270-274, 2008

16. Eustacchio S, Leber K, Trummer M, Unger F, Pendl G: Gamma Knife radiosurgery for glomus jugulare tumours. Acta Neurochir (Wien) 141:811-818, 1999

17. Eustacchio S, Trummer M, Unger F, Schröttner O, Sutter B, Pendl G: The role of Gamma Knife radiosurgery in the management of glomus jugular tumours. Acta Neurochir Suppl 84:91-97, 2002

18. Fayad JN, Keles B, Brackmann DE: Jugular foramen tumors: clinical characteristics and treatment outcomes. Otol Neurotol 31:299-305, 2010

19. Feigl GC, Horstmann GA: Intracranial glomus jugulare tumors: volume reduction with Gamma Knife surgery. J Neurosurg 105 Suppl:161-167, 2006

20. Foote RL, Coffey RJ, Gorman DA, Earle JD, Schomberg PJ, Kline RW, et al: Stereotactic radiosurgery for glomus jugulare tumors: a preliminary report. Int J Radiat Oncol Biol Phys 38:491-495, 1997

21. Foote RL, Pollock BE, Gorman DA, Schomberg PJ, Stafford SL, Link MJ, et al: Glomus jugulare tumor: tumor control and complications after stereotactic radiosurgery. Head Neck 24:332-339, 2002

22. Fussey JM, Kemeny AA, Sankar S, Rejali D: Successful management of a catecholamine-secreting glomus jugulare tumor with radiosurgery alone. J Neurol Surg B Skull Base 74:399-402, 2013

23. Gandía-González ML, Kusak ME, Moreno NM, Sárraga JG, Rey G, Álvarez RM: Jugulotympanic paragangliomas treated with Gamma Knife radiosurgery: a single-center review of 58 cases. J Neurosurg 121:1158-1165, 2014

24. Ganz JC, Abdelkarim K: Glomus jugulare tumours: certain clinical and radiological aspects observed following Gamma Knife radiosurgery. Acta Neurochir (Wien) 151:423-426, 2009

25. Gartrell BC, Hansen MR, Gantz BJ, Gluth MB, Mowry SE, Aagaard-Kienitz BL, et al: Facial and lower cranial neuropathies after preoperative embolization of jugular foramen lesions with ethylene vinyl alcohol. Otol Neurotol 33:12701275,2012
26. Gaynor BG, Elhammady MS, Jethanamest D, Angeli SI, Aziz-Sultan MA: Incidence of cranial nerve palsy after preoperative embolization of glomus jugulare tumors using Onyx. J Neurosurg 120:377-381, 2014

27. Genç A, Bicer A, Abacioglu U, Peker S, Pamir MN, Kilic T: Gamma Knife radiosurgery for the treatment of glomus jugulare tumors. J Neurooncol 97:101-108, 2010

28. Gerosa M, Visca A, Rizzo P, Foroni R, Nicolato A, Bricolo A: Glomus jugulare tumors: the option of Gamma Knife radiosurgery. Neurosurgery 59:561-569, 2006

29. Gottfried ON, Liu JK, Couldwell WT: Comparison of radiosurgery and conventional surgery for the treatment of glomus jugulare tumors. Neurosurg Focus 17(2):E4, 2004

30. Guss ZD, Batra S, Li G, Chang SD, Parsa AT, Rigamonti D, et al: Radiosurgery for glomus jugulare: history and recent progress. Neurosurg Focus 27(6):E5, 2009

31. Guss ZD, Batra S, Limb CJ, Li G, Sughrue ME, Redmond $\mathrm{K}$, et al: Radiosurgery of glomus jugulare tumors: a metaanalysis. Int J Radiat Oncol Biol Phys 81:e497-e502, 2011

32. Hao HX, Khalimonchuk O, Schraders M, Dephoure N, Bayley JP, Kunst H, et al: SDH5, a gene required for flavination of succinate dehydrogenase, is mutated in paraganglioma. Science 325:1139-1142, 2009

33. Harati A, Deitmer T, Rohde S, Ranft A, Weber W, Schultheiß $\mathrm{R}$ : Microsurgical treatment of large and giant tympanojugular paragangliomas. Surg Neurol Int 5:179, 2014

34. Heth J: The basic science of glomus jugulare tumors. Neurosurg Focus 17(2):E2, 2004

35. Jackson CG, Glasscock ME III, Harris PF: Glomus tumors. Diagnosis, classification, and management of large lesions. Arch Otolaryngol 108:401-410, 1982

36. Jackson CG, Glasscock ME III, McKennan KX, Koopmann CF Jr, Levine SC, Hays JW, et al: The surgical treatment of skull-base tumors with intracranial extension. Otolaryngol Head Neck Surg 96:175-185, 1987

37. Jackson CG, McGrew BM, Forest JA, Netterville JL, Hampf CF, Glasscock ME III: Lateral skull base surgery for glomus tumors: long-term control. Otol Neurotol 22:377-382, 2001

38. Jansen JC, van den Berg R, Kuiper A, van der Mey AG, Zwinderman AH, Cornelisse CJ: Estimation of growth rate in patients with head and neck paragangliomas influences the treatment proposal. Cancer 88:2811-2816, 2000

39. Jordan JA, Roland PS, McManus C, Weiner RL, Giller CA: Stereotactic radiosurgery for glomus jugulare tumors. Laryngoscope 110:35-38, 2000

40. Kemeny AA: Contemporary management of jugular paragangliomas (glomus tumours): microsurgery and radiosurgery. Acta Neurochir (Wien) 151:419-421, 2009

41. Kovacova A, Ghazi-Nouri S, Lee P: Glomus jugulare: a rare cause of facial nerve palsy. Orbit 32:214-216, 2013

42. Lee CC, Pan DH, Wu JC, Chung WY, Wu HM, Yang HC, et al: Gamma Knife radiosurgery for glomus jugulare and tympanicum. Stereotact Funct Neurosurg 89:291-298, 2011

43. Li G, Chang S, Adler JR Jr, Lim M: Irradiation of glomus jugulare tumors: a historical perspective. Neurosurg Focus 23(6):E13, 2007

44. Liscak R, Urgosik D, Chytka T, Simonova G, Novotny J Jr, Vymazal J, et al: Leksell Gamma Knife radiosurgery of the jugulotympanic glomus tumor: long-term results. J Neurosurg 121 Suppl:198-202, 2014

45. Liscák R, Vladyka V, Wowra B, Kemeny A, Forster D, Burzaco JA, et al: Gamma Knife radiosurgery of the glomus jugulare tumour - early multicentre experience. Acta Neurochir (Wien) 141:1141-1146, 1999

46. Makiese O, Chibbaro S, Marsella M, Tran Ba Huy P, George B: Jugular foramen paragangliomas: management, outcome and avoidance of complications in a series of 75 cases. Neurosurg Rev 35:185-194, 2012

47. Manolidis S, Shohet JA, Jackson CG, Glasscock ME III: Malignant glomus tumors. Laryngoscope 109:30-34, 1999 
48. Miller JP, Semaan M, Einstein D, Megerian CA, Maciunas RJ: Staged Gamma Knife radiosurgery after tailored surgical resection: a novel treatment paradigm for glomus jugulare tumors. Stereotact Funct Neurosurg 87:31-36, 2009

49. Murphy TP, Brackmann DE: Effects of preoperative embolization on glomus jugulare tumors. Laryngoscope 99:12441247,1989

50. Netterville JL, Civantos FJ: Rehabilitation of cranial nerve deficits after neurotologic skull base surgery. Laryngoscope 103 (11 Pt 2 Suppl 60):45-54, 1993

51. Niemann S, Müller U: Mutations in SDHC cause autosomal dominant paraganglioma, type 3. Nat Genet 26:268-270, 2000

52. Oldring D, Fisch U: Glomus tumors of the temporal region: surgical therapy. Am J Otol 1:7-18, 1979

53. Pareschi R, Righini S, Destito D, Raucci AF, Colombo S: Surgery of glomus jugulare tumors. Skull Base 13:149-157, 2003

54. Patel SJ, Sekhar LN, Cass SP, Hirsch BE: Combined approaches for resection of extensive glomus jugulare tumors. A review of 12 cases. J Neurosurg 80:1026-1038, 1994

55. Pollock BE: Stereotactic radiosurgery in patients with glomus jugulare tumors. Neurosurg Focus 17(2):E10, 2004

56. Prabhu SS, DeMonte F: Complete resection of a complex glomus jugulare tumor with extensive venous involvement. Case report. Neurosurg Focus 17(2):E12, 2004

57. Ramina R, Maniglia JJ, Fernandes YB, Paschoal JR, Pfeilsticker LN, Neto MC, et al: Jugular foramen tumors: diagnosis and treatment. Neurosurg Focus 17(2):E5, 2004

58. Sanna M, Jain Y, De Donato G, Rohit, Lauda L, Taibah A: Management of jugular paragangliomas: the Gruppo Otologico experience. Otol Neurotol 25:797-804, 2004

59. Saringer W, Khayal H, Ertl A, Schoeggl A, Kitz K: Efficiency of Gamma Knife radiosurgery in the treatment of glomus jugulare tumors. Minim Invasive Neurosurg 44:141-146, 2001

60. Sen C, Hague K, Kacchara R, Jenkins A, Das S, Catalano P: Jugular foramen: microscopic anatomic features and implications for neural preservation with reference to glomus tumors involving the temporal bone. Neurosurgery 48:838-848, 2001

61. Sharma MS, Gupta A, Kale SS, Agrawal D, Mahapatra AK, Sharma BS: Gamma Knife radiosurgery for glomus jugulare tumors: therapeutic advantages of minimalism in the skull base. Neurol India 56:57-61, 2008

62. Sheehan J, Kondziolka D, Flickinger J, Lunsford LD: Gamma Knife surgery for glomus jugulare tumors: an intermediate report on efficacy and safety. J Neurosurg 102 Suppl:241-246, 2005

63. Sheehan JP, Tanaka S, Link MJ, Pollock BE, Kondziolka $\mathrm{D}$, Mathieu D, et al: Gamma Knife surgery for the management of glomus tumors: a multicenter study. J Neurosurg 117:246-254, 2012
64. van der Mey AG, Frijns JH, Cornelisse CJ, Brons EN, van Dulken H, Terpstra HL, et al: Does intervention improve the natural course of glomus tumors? A series of 108 patients seen in a 32-year period. Ann Otol Rhinol Laryngol 101:635-642, 1992

65. Varma A, Nathoo N, Neyman G, Suh JH, Ross J, Park J, et al: Gamma Knife radiosurgery for glomus jugulare tumors: volumetric analysis in 17 patients. Neurosurgery 59:1030-1036, 2006

66. Wanna GB, Sweeney AD, Carlson ML, Latuska RF, Rivas A, Bennett ML, et al: Subtotal resection for management of large jugular paragangliomas with functional lower cranial nerves. Otolaryngol Head Neck Surg 151:991-995, 2014

67. Watkins LD, Mendoza N, Cheesman AD, Symon L: Glomus jugulare tumours: a review of 61 cases. Acta Neurochir (Wien) 130:66-70, 1994

68. Whitfield PC, Grey P, Hardy DG, Moffat DA: The surgical management of patients with glomus tumours of the skull base. Br J Neurosurg 10:343-350, 1996

69. Willen SN, Einstein DB, Maciunas RJ, Megerian CA: Treatment of glomus jugulare tumors in patients with advanced age: planned limited surgical resection followed by staged Gamma Knife radiosurgery: a preliminary report. Otol Neurotol 26:1229-1234, 2005

\section{Disclosures}

The authors report no conflict of interest concerning the materials or methods used in this study or the findings specified in this paper.

\section{Author Contributions}

Conception and design: Ibrahim, Yianni, Rowe. Acquisition of data: Ibrahim. Analysis and interpretation of data: Ibrahim, Ammori, Grainger. Drafting the article: Ibrahim, Yianni. Critically revising the article: Ibrahim, Ammori, Yianni, Rowe, Radatz. Reviewed submitted version of manuscript: all authors. Approved the final version of the manuscript on behalf of all authors: Ibrahim. Statistical analysis: Ibrahim, Ammori.

\section{Supplemental Information}

\section{Previous Presentations}

Portions of this work were presented as an oral presentation at the British Radiosurgery Society meeting held in Sheffield, United Kingdom, on May 21, 2013.

\section{Correspondence}

Ramez Ibrahim, National Centre for Stereotactic Radiosurgery, Royal Hallamshire Hospital, Glossop Rd., Sheffield S10 2JF, United Kingdom. email: ramezibrahim@hotmail.com. 